\title{
Polymeric micelles loaded with platinum anticancer drugs target preangiogenic micrometastatic niches associated with inflammation
}

Hailiang $\mathrm{Wu}^{\mathrm{a}}$, Horacio Cabral ${ }^{\mathrm{a}^{*}}$, Kazuko Toh ${ }^{\mathrm{b}}$, Peng Mi ${ }^{\mathrm{c}}$, Yi-Chun Chen ${ }^{\mathrm{d}}$, Yu Matsumoto ${ }^{\mathrm{b}}$, Naoki Yamada ${ }^{\mathrm{d}}$,

Xueying Liu ${ }^{b}$, Hiroaki Kinoh ${ }^{a}$, Yutaka Miura ${ }^{b}$, Mitsunobu R. Kano ${ }^{\mathrm{e}}$, Hiroshi Nishihara ${ }^{\mathrm{f}}$, Nobuhiro Nishiyama ${ }^{\mathrm{c}}$ and Kazunori Kataoka $\mathrm{a}^{\mathrm{a}, \mathrm{b}, \mathrm{d} \mathrm{d}^{*}}$

${ }^{a}$ Department of Bioengineering, Graduate School of Engineering, The University of Tokyo, 7-3-1 Hongo, Bunkyo-ku, Tokyo 113-8656, Japan.

${ }^{\mathrm{b}}$ Center for Disease Biology and Integrative Medicine, Graduate School of Engineering, The University of Tokyo, 7-3-1 Hongo, Bunkyo-ku, Tokyo 113-8656, Japan.

${ }^{\mathrm{c}}$ Polymer Chemistry Division, Chemical Resources Laboratory, Tokyo Institute of Technology, R1-11, 4259 Nagatsuta, Midori-ku, Yokohama 226-8503, Japan

${ }^{\mathrm{d}}$ Department of Materials Engineering, Graduate School of Engineering, The University of Tokyo, 7-3-1 Hongo, Bunkyo-ku, Tokyo 113-8656, Japan.

${ }^{\mathrm{e}}$ Department of Pharmaceutical Biomedicine, Graduate School of Medicine, Dentistry, and Pharmaceutical Sciences, Okayama University, 1-1-1 Tsushima-naka, Kita-ku, Okayama 700-8530, Japan

${ }^{\mathrm{f}}$ Laboratory of Translational Pathology, Hokkaido University School of Medicine, North 15, West 7, Kita-ku, Sapporo, 060-8638, Japan

*Corresponding authors

Kazunori Kataoka, PhD

Department of Materials Engineering, Graduate School of Engineering, The University of Tokyo, 7-3-1 Hongo, Bunkyo-ku, Tokyo 113-8656, Japan

Tel: +81-3-5841-7138; Fax: +81-3-5841-7139

E-mail: kataoka@bmw.t.u-tokyo.ac.jp

Horacio Cabral, $\mathrm{PhD}$

Department of Bioengineering, Graduate School of Engineering, The University of Tokyo, 7-3-1 Hongo, Bunkyo-ku, Tokyo 113-8656, Japan.

Tel: +81-3-5841-6142;

E-mail: horacio@bmw.t.u-tokyo.ac.jp

(C) 2014. This manuscript version is made available under the Elsevier user license 


\begin{abstract}
Nanocarriers have been used for specific delivery of therapeutic agents to solid tumors based on the enhanced permeability and retention in cancerous tissues. Despite metastasis is the main reason of cancer-related death and a priority for nanocarrier-based therapies, the targeting ability of nanocarriers to the metastatic disease is poorly understood, especially for preangiogenic micrometastases as nanocarriers usually use the malignant neovasculature for enhancing their accumulation. Thus, herein, we studied the ability of micellar nanocarriers incorporating (1,2-diaminocyclohexane)platinum(II) (DACHPt) for treating liver metastases of bioluminescent murine colon adenocarcinoma C-26, during overt and preangiogenic metastatic stages. After intravenous injection, DACHPt-loaded micelles (DACHPt $/ \mathrm{m}$ ) effectively inhibited the tumor growth in both metastatic tumor models. While the anticancer activity of the micelles against overt metastases was associated with their selective accumulation in cancerous tissues having neovasculature, the ability of DACHPt/m to target preangiogenic metastases was correlated with the inflammatory microenvironment of the niche. This targeting capability of polymeric micelles to preangiogenic metastasis may provide a novel approach for early diagnosis and treatment of metastases.
\end{abstract}

Keywords: drug delivery system, chemotherapy, cyclooxygenase-2, oxaliplatin, metastatic niche

\title{
1. Introduction
}

Metastases account for approximately $90 \%$ of the deaths from cancer [1], with an estimated projection of 13.1 million deaths by 2030 [2]. Even though this situation is driving a rapid increase in the demand for effective treatments, current clinical therapies often display limited activity against metastatic lesions [3,4], as they are mainly focused on inhibiting the growth of primary tumors, rather than targeting the pathologic paths of metastases. For developing efficient therapies against metastatic disease, the later stages of the metastatic cascade [5], including disseminated dormant cells, preangiogenic micrometastases and vascularized metastases, appear as the suitable clinical targets $[3,4,6]$, since the initial steps of metastasis are usually completed by the time cancer is diagnosed. Thus, therapeutic agents that limit the proliferation and survival of the metastatic foci will provide the utmost therapeutic impact $[3,4,6]$, Nevertheless, because the physical barriers of the metastatic microenvironment may restrain the accumulation of drugs [7], effective targeting of such highly active drugs against metastatic tumors may be decisive for their activity. In this way, targeted therapies by using nano-scaled drug carriers are expected to provide significant improvements in the delivery of active agents to the metastatic disease [8], and nanocarriers capable of restricting the development and growth of metastases have the potential to achieve the greatest clinical benefit.

Nanocarriers have shown selective accumulation in solid tumors by taking advantage of the augmented permeability of the tumor blood vessels, and their enhanced retention due to inefficient lymphatic drainage in cancer tissues, so called the enhanced permeability and retention (EPR) effect [9]. Although most studies have focused on the targeting of nanocarriers to primary tumors, several reports have demonstrated that it may also be possible for nanocarriers to accumulate in overt macrometastasis with already developed vasculature [10-12]. Nevertheless, despite that the transition between preangiogenic micrometastases and vascularized macrometastases constitutes a major therapeutic target in the metastatic cascade, the ability of nanocarriers for targeting 
preangiogenic metastatic sites remains unknown. Although such micrometastases lack of neovasculature, they offer distinct characteristics that can be exploited for effective targeting by using nanocarriers. Accordingly, preangiogenic metastatic niches consisting of metastatic cells and their surrounding stroma, may present inflammatory microenvironment [3-6, 13] produced by metastatic cells, metastasis-associated immune cells and stromal cells, which mediates the metastatic development by promoting metastasis angiogenesis [13]. Because this inflammatory microenvironment can induce vascular permeability, involving both intraendothelial transport and interendothelial leakage of macromolecules [3, 14], the accumulation of systemically injected nanocarriers in such preangiogenic metastatic foci may be facilitated, thus, providing a specific target for selective treatment of preangiogenic micrometastases.

Among promising nanocarriers, core-shell self-assembled polymeric micelles have shown unique advantages for tumor targeting $[15,16]$, such as high loading capacity of their core, their biocompatible PEG shell, relatively small size, controlled drug release, prolonged blood circulation and enhanced accumulation in solid tumors after intravenous injection $[15,16]$. Several polymeric micelles incorporating anticancer agents are being studied in clinical trials, demonstrating high efficacy against several malignancies and reduced side effects [17, 18]. Therefore, in this study, we focused on the ability of polymeric micelles incorporating anticancer agents for targeting vascularized macrometastases and preangiogenic micrometastases. Moreover, as liver is the most frequent site for metastasis from several prevalent human malignancies [19], in particular for colorectal cancer (CRC) [20], being its major cause of death [21], we studied the efficacy of the micelles in syngeneic models of liver metastasis, which were prepared by inoculating bioluminescent murine colon adenocarcinoma C-26 expressing luciferase (C-26-luc) into the spleen of Balb/c mice. We have used the model of intrasplenic injection of cancer cells, as it allowed us to precisely regulate with high repeatability the formation of metastases from the preangiogenic to the overt stage. Also, because oxaliplatin is the first-line clinical treatment of advanced colorectal cancer presenting hepatic metastasis [20], we used polymeric micelles incorporating the parent complex of oxaliplatin, i.e. (1,2-diaminocyclohexane)platinum(II) (DACHPt), in their core after polymer-metal complexation with the carboxylates of poly(ethylene glycol)-b-poly(glutamic acid) [PEG-b-P(Glu)] copolymers [22]. DACHPt is sustainedly released from the micelles by the ligand exchange with the chloride ions in the media [22], discharging approximately $30 \%$ of the loaded drugs after $48 \mathrm{~h}$ in physiological conditions, while the micelle form is retained [23]. DACHPt-loaded micelles (DACHPt $/ \mathrm{m}$ ) have demonstrated selective tumor accumulation and high antitumor activity in several tumor models [23-28], and are under phase I clinical trials. The results of the present study showed that systemically administered DACHPt $/ \mathrm{m}$ can significantly inhibit the growth of both overt and preangiogenic hepatic metastases by selectively accumulating in the metastatic foci, indicating the potential of polymeric micelles for treating both macro- and micrometastatic disease in liver.

\section{MATERIALS AND METHODS}

\subsection{Materials}

Oxaliplatin, $\gamma$-Benzyl L-glutamate and Dulbecco's modified Eagle's medium (DMEM) were acquired from Sigma-Aldrich Co., Inc. (St Louis, MO). Bis(trichloromethyl) carbonate (triphosgene) was purchased from Tokyo Kasei Kogyo, Co. Ltd. (Tokyo, Japan). N,N-Dimethylformamide (DMF) was obtained from Wako Pure Chemicals Industries, Ltd. (Tokyo, Japan). Dichloro(1,2-diammino cyclohexane) platinum (II) was purchased from W.C. Heraeus GmbH (Hanau, Germany). 
$\alpha$-Methoxy- $\omega$-amino-poly(ethylene glycol) $\left(\mathrm{CH}_{3} \mathrm{O}-\mathrm{PEG}-\mathrm{NH}_{2} ; \mathrm{MW}: 12,000\right)$ was bought from NOF Co., Ltd. (Tokyo, Japan). Anti-Cytokeratin 20 antibody (ab76126) and anti-CD68 antibody (ab31630) were purchased from Abcam (Cambridge, MA), anti- $\alpha$-SMA antibody (Sigma-Aldrich; A2547). Blocking One Buffer was purchased from Nakalai Tesque Co., Ltd. (Tokyo, Japan). Alexa 647- and Alexa 488-secondary antibodies, as well as Alexa 647- and Alexa 555-succinimidyl esters were purchased from Invitrogen Co., Inc. (Carlsbad, CA).

\subsection{Cell line}

Murine colon adenocarcinoma cells $\mathrm{C}-26$ were cultured at $37{ }^{\circ} \mathrm{C}$ under $5 \% \mathrm{CO}_{2}$ in DMEM with $10 \%$ FBS. These cells were transfected with pEF6 vector (Invitrogen Co., Inc.; Carlsbad, CA) containing a firefly-luciferase gene by Lipofectamine 2000 (Invitrogen). Clones resistant to G418 (Wako; Tokyo, Japan) were selected and their luciferase activities were determined using IVIS. C-26 bearing GFP was obtained from Anticancer Japan (Tokyo, Japan).

\subsection{Animals}

Immunocompetent Balb/c at 6 week of age were used as host of tumor injections. All animals were obtained from Charles River Laboratories (Tokyo, Japan), and treated in accordance with the policies of the Animal Ethics Committee of the University of Tokyo.

\subsection{Synthesis of block copolymer and homopolymer}

Poly(ethylene glycol)- $b$-poly(L-glutamic acid) [PEG-b-P(Glu)] copolymer $\left[\mathrm{MW}_{\mathrm{PEG}}=12,000\right.$; polymerization degree of $\mathrm{P}(\mathrm{Glu})=40$ ] and poly(L-glutamic acid) homopolymer were synthesized according to the previously described synthetic method of ring opening polymerization of $\gamma$-benzyl L-glutamate N-carboxyanhydride (BLG-NCA) [25, 48]. The molecular weight distribution (Mw/Mn) of PEG- $b$-poly(benzyl L-glutamate) (PBLG) and PBLG thus prepared was determined to be 1.09 and 1.16 by gel permeation chromatography (GPC) [column, TSK-gel G3000HHR, G4000HHR (Tosoh); eluent, DMF containing $10 \mathrm{mM} \mathrm{LiCl}$; flow rate, $0.8 \mathrm{ml} / \mathrm{min}$; detector, refractive index; temperature, $25^{\circ} \mathrm{C}$ ]. The degree of polymerization of PEG- $b$-PBLG and PBLG was confirmed by comparing the proton ratios of the methylene units in PEG $(\delta=3.7 \mathrm{ppm})$ or the methylene units in the butyl end $(\delta=1.35 \mathrm{ppm}$ and $\delta=1.55 \mathrm{ppm})$, respectively, with the phenyl groups of PBLG $(\delta=7.3 \mathrm{ppm})$ by ${ }^{1} \mathrm{H}-\mathrm{NMR}$ spectroscopy [JEOL EX270 (JEOL Inc., Tokyo, Japan); solvent: DMSO- $d_{6}$; temperature: $70{ }^{\circ} \mathrm{C}$ ]. The degree of polymerization was determined to be 40 for both PEG- $b$-PBLG and PBLG. PEG- $b$-PBLG was deprotected by mixing with $0.5 \mathrm{~N} \mathrm{NaOH}$ at room temperature to obtain PEG- $b-\mathrm{P}(\mathrm{Glu})$, while PBLG was deprotected in a suspension of THF/ $0.5 \mathrm{~N}$ $\mathrm{NaOH}$ to obtain $\mathrm{P}(\mathrm{Glu})$. Complete deprotection was confirmed by ${ }^{1} \mathrm{H}-\mathrm{NMR}$ spectroscopy (solvent: $\mathrm{D}_{2} \mathrm{O}$; temperature: $25^{\circ} \mathrm{C}$ ). For the preparation of fluorescent labeled PEG- $b$-P(Glu), Alexa 647- and Alexa 555-NHS was mixed with the copolymer in DMSO for $3 \mathrm{~h}$, dialyzed against water and purified by column filtration.

\subsection{Preparation of DACHPt-loaded micelles (DACHPt/m) with 30-nm and 70-nm diameter}

$\mathrm{DACHPt} / \mathrm{m}$ with 30- and 70-nm diameter were prepared according to the previously described method [25]. Briefly, DACHPt $(5 \mathrm{mM})$ was suspended in water and mixed with $\mathrm{AgNO}_{3}$ $\left(\left[\mathrm{AgNO}_{3}\right] /[\mathrm{DACHPt}]=1\right)$ to form DACHPt nitrate chloride. The solution was maintained in dark at $25{ }^{\circ} \mathrm{C}$ for $24 \mathrm{~h}$. Then, $\mathrm{AgCl}$ precipitates were removed and DACHPt nitrate chloride solution was mixed with PEG- $b-\mathrm{P}(\mathrm{Glu})([\mathrm{Glu}]=5 \mathrm{mM}$; [DACHPt $] /[\mathrm{Glu}]=1.0)$ for $30-\mathrm{nm}$ micelles and with a 
mixture of PEG- $b-\mathrm{P}(\mathrm{Glu})$ and $\mathrm{P}(\mathrm{Glu}) \quad([\mathrm{Glu}]=5 \mathrm{mM} ; \quad[\mathrm{DACHPt}] /[\mathrm{Glu}]=1.0$; $[\mathrm{P}(\mathrm{Glu})] /[\mathrm{PEG}-\mathrm{b}-\mathrm{P}(\mathrm{Glu})]=0.1$ ) for $70-\mathrm{nm}$ micelles. The mixtures were reacted for $120 \mathrm{~h}$ to obtain DACHPt $/ \mathrm{m}$. Fluorescent labeled micelles were prepared in a similar way by using Alexa 555- and Alexa 647-labeled PEG-b-P(Glu). Micelles were purified by ultrafiltration (Molecular weight cut-off: $30 \mathrm{kDa}$ ). The size distribution of the micelles was determined by dynamic light scattering (DLS) using a Zetasizer Nano-ZS instrument (Malvern Instruments, Malvern, UK) and transmission electron microscopy (TEM) after staining with $1 \%$ uranyl acetate. Accordingly, the z-average diameters by volume of 30- and 70-nm micelles were approximately 30- and 69-nm, respectively. The size distribution by TEM showed smaller diameters, as the PEG shell of the micelles cannot be detected. Thus, the number-average diameter of 30-nm micelles by TEM was approximately $14 \mathrm{~nm}$ (Supporting Figure S4a), and for 70-nm micelles, it was nearly $40 \mathrm{~nm}$ (Supporting Figure S4b). The platinum content of DACHPt/m was assessed by ion-coupled plasma mass spectrometry (Hewlett Packard 4500 ICP-MS, Hewlett Packard, USA).

\subsection{Preparation of orthotopic and metastatic tumor models}

C-26-luc cells $\left(5 \times 10^{4}\right)$ were injected into the colon wall of Balb/c mice to develop orthotopic tumor model. To establish hepatic metastatic model of colon cancer, $5 \times 10^{4} \mathrm{C}$-26-luc cells were injected into the spleens of Balb/c mice. Spleens were removed $24 \mathrm{~h}$ post inoculation to prevent tumor formation in the spleen. The glutamate pyruvate transaminase (GPT) and glutamic oxaloacetic transaminase (GOT) levels in plasma, which was collected from healthy mice or metastases-bearing mice every two days after inoculation of the cancer cells, were assessed to determine the extent of hepatic injury by using a Fuji Dri-Chem 4000i analyzer (Fujifilm, Tokyo, Japan).

\subsection{Histology}

Tumor tissues from the orthotopic tumor model and liver tissues from metastatic model were harvested. For studying the progression of liver metastasis, the tissues were fixed in paraffin and sectioned for H\&E staining. For immunofluorescence studies, liver tissues were preserved in OCT and fix by $4 \%$ paraformaldehyde after sectioning. The sections were reacted with anti-Cytokeratin 20 antibody for C-26 tumor, anti- $\alpha$-SMA antibody for stellate cells and anti-CD68 antibody for Kupffer cells. Sections were subsequently stained with secondary antibodies conjugated with Alexa 647 or 488 anti-rat/rabbit IgG. Images were obtained by using an Olympus AX80 microscope for H\&E staining and a Zeiss LSM780 Meta confocal microscope for immunofluorescence.

\subsection{Antitumor activity assay}

The antitumor activity of oxaliplatin and micelles was evaluated against orthotopic colon tumors, overt and preangiogenic liver metastasis of colon cancer. Thus, tumor-bearing mice $(\mathrm{n}=5)$ were injected with oxaliplatin at $4 \mathrm{mg} / \mathrm{kg}$ or $8 \mathrm{mg} / \mathrm{kg}$, and 30 - and $70-\mathrm{nm} \mathrm{DACHPt} / \mathrm{m}$ at $3 \mathrm{mg} / \mathrm{kg}$, every 3 days in a total of 3 times. For orthotopic tumors and overt metastases, the treatment was started 9 days after inoculation. At this point, the overt metastases were approximately $10 \mathrm{~mm}^{3}$, as confirmed by macroscopic and histological observations. For preangiogenic metastases model, the treatment began 3 days after inoculation. The burden of C-26-luc tumors was followed by bioluminescent imaging. Thus, mice bearing orthotopic tumors and overt liver metastasis were intraperitoneally injected $50 \mathrm{mg} / \mathrm{kg}$ luciferin (Promega; Madison, WI), while mice bearing micrometastasis were intraperitoneally injected $100 \mathrm{mg} / \mathrm{kg}$ luciferin. Imaging was performed 10 
min after injection by using IVIS SPECTRUM in vivo photon-counting device (Caliper Life Sciences; Hopkinton, MA, USA), and the bioluminescent signal was measured every 2 or 3 days. Images were quantified as photon counts/second using the Living Image software (Caliper Life Sciences; Hopkinton, MA, USA). Antitumor activities were evaluated in terms of relative bioluminescence units to the day when the treatment started. Moreover, the survival of mice having orthotopic and overt metastasis was assessed to confirm the efficacy of the drugs.

To study the effect of inflammation on the antitumor activity of oxaliplatin and micelles in the preangiogenic metastasis model, $5 \mathrm{mg} / \mathrm{kg}$ Celecoxib (COX-2 inhibitor ; Sigma-Aldrich; Tokyo, Japan) in 4\% DMSO was injected intraperitoneally $24 \mathrm{~h}$ before the injection of the anticancer drugs. Then, oxaliplatin and micelles were administered as abovementioned.

\subsection{Tissue distribution of fluorescent micelles}

Mice bearing orthotopic tumors, as well as mice bearing overt or preangiogenic C-26-luc hepatic metastases, were intravenously injected with Alexa 647-labeled DACHPt $/ \mathrm{m}$. Twenty four-hours later, tissues were harvested and imaged using IVIS SPECTRUM in vivo photon-counting device (Caliper Life Sciences; Hopkinton, MA, USA). The signal of fluorescent labeled-DACHPt/m was detected using 650/668 nm ex/em filters.

\subsection{In vivo confocal laser scanning microscopy (CLSM)}

The in vivo microscopies were done using a Nikon A1R confocal laser scanning microscope system attached to an upright Eclipse FN1 (Nikon Corp., Tokyo, Japan) [29], with a high-speed resonant scanner, which allows the acquisition of 30 frames/s. For intravital imaging of liver tissues, mice were anesthetized with 2\% isoflurane (Abbott Japan Co., Ltd., Tokyo, Japan) and liver tissues were accessed following exteriorization through skin incision. Then, a custom-designed height adjustable coverslip holder was placed onto the liver and perpendicular to the objective lens (Supporting Figure S5). For studying the real-time accumulation of DACHPt/m in the metastases, mice bearing micrometastases of C-26-GFP were intravenously injected with Alexa 647-labeled DACHPt/m having 30-nm diameter. C-26-GFP metastases were detected using 488/510 nm excitation/emission filters and Alexa 647-labeled micelles were detected using 650/668 nm ex/em filters. For imaging the expression of COX-2 in the metastatic niches, COX-2 probe (Caliper Life Sciences; Hopkinton, MA, USA) at the recommended dose $(2 \mathrm{mg} / \mathrm{kg})$ was injected intraperitoneally $3 \mathrm{~h}$ before imaging and detected using 650/668 nm ex/em filters. For imaging the accumulation of micelles in COX-2 positive metastatic niches, COX-2 probe at $2 \mathrm{mg} / \mathrm{kg}$ was injected intraperitoneally and Alexa 555-labeled DACHPt $/ \mathrm{m}$ micelles were intravenously injected in mice bearing C-26-GFP micrometastases. Fluorescence intensity in all microscopies was quantified using NIS elements (Nikon).

\subsection{Statistical analysis}

Statistical evaluation was done by Student's $t$-test. P values lower than 0.05 were considered as statistically significant. Data represent the means \pm SE. The statistical analysis of the overall survival was calculated using the log rank test (Mantel-Cox) using GraphPad Prism software (GraphPad Software (La Jolla, CA)).

\section{Results}




\subsection{Efficacy of DACHPt/m in an orthotopic model of colon adenocarcinoma}

We firstly studied the activity of DACHPt/m in vascularized primary tumors of C-26-luc cells for confirming that the in vivo efficacy of the micelles against this cell line as well as for determining the ability of $\mathrm{DACHPt} / \mathrm{m}$ to specifically accumulate in such tumors. Thus, bioluminescent orthotopic colon tumors were prepared by injecting Colon 26-luc cells into the colonic wall of Balb/c mice (Supporting Figure S1a). The preparation of the model was confirmed by measuring the bioluminescent signal from the tumors (Supporting Figure S1b), as well as by histology (Supporting Figure S1c). Five days after inoculation, mice were treated with PBS, free oxaliplatin at $8 \mathrm{mg} / \mathrm{kg}$, i.e. the maximum tolerated dose, and DACHPt $/ \mathrm{m}$ at $3 \mathrm{mg} / \mathrm{kg}$ on days 0,2 , and 4 via intravenous injection, and the bioluminescence intensity from C-26-luc tumors was quantified every 2 days by using in vivo imaging system (IVIS). The antitumor activity was followed for 14 days, which was the day when the control mice treated with PBS started to die. At this time point, DACHPt/m showed significantly higher efficacy against orthotopic tumors than the free oxaliplatin (Figure 1a; $\mathrm{P}<0.05$ ), restricting the bioluminescent signal in the peritoneal region (Figure 1b). In addition, by assessing the survival rate of these mice, we revealed that DACHPt $/ \mathrm{m}$ considerably prolonged the survival for more than 28 days (Figure $1 \mathrm{c} ; \mathrm{P}<0.001 \log$ rank test), while at day 26, all mice treated with PBS or oxaliplatin were dead. These data support the enhanced activity of DACHPt/m against orthotopic colon tumors from C-26-luc cells, and agreed with our previous observations in a subcutaneous C-26 tumor model, where DACHPt/m were significantly more effective than oxaliplatin in suppressing the tumors $[23,25]$.

By using DACHPt/m labeled with Alexa 647, we evaluated the tissue distribution through fluorescence imaging. Thus, tumor-bearing mice were intravenously injected with fluorescent-labeled micelles, and the tissue distribution was monitored $24 \mathrm{~h}$ later by ex vivo imaging with IVIS. The fluorescence from the micelles was detectable in tumor and organs, such as colon, liver, kidney and spleen. However, the strong fluorescent signal from the micelles at the position of the luminescent signal from the C-26-luc tumor, which was higher than the fluorescent signal in other tissues (Figure 1d), indicated the preferential accumulation of the micelles in the orthotopic tumor. Accordingly, we have previously reported that approximately $10 \%$ of the injected micelles accumulated in a gram of tumor tissue $[23,25]$, while the distribution to other organs was limited. These results illustrate the ability of DACHPt $/ \mathrm{m}$ to accumulate in tumors based on the EPR effect and achieve significant in vivo antitumor effect, which in this case can be directly assessed by following the bioluminescent signal from C-26-luc cells. 


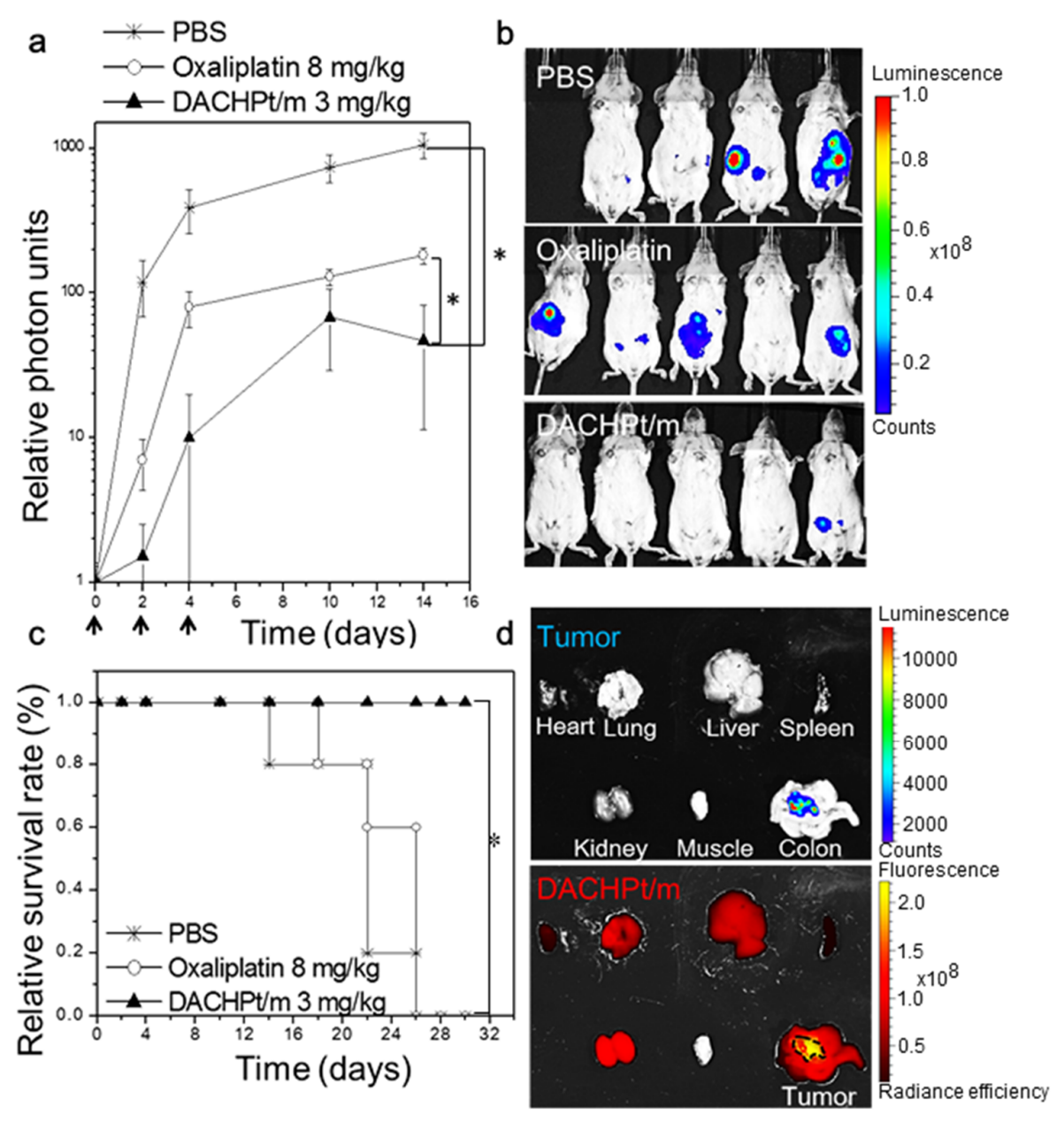

Figure 1. DACHPt-loaded micelles (DACHPt/m) inhibit the growth of orthotopic C-26-luc tumors. (a), Longitudinal quantification analysis of bioluminescence signal of the mice treated with oxaliplatin or DACHPt/m on days 0,2 and 4. Crosses, PBS; open circles, oxaliplatin at $8 \mathrm{mg} / \mathrm{kg}$; filled triangles, DACHPt $/ \mathrm{m}$ at $3 \mathrm{mg} / \mathrm{kg}$. Data are expressed as mean $\pm \mathrm{SE}(\mathrm{n}=5)$. Arrows indicate days of injection. ${ }^{*} \mathrm{P}<0.05$. (b), Bioluminescent images of representative mice from PBS-, oxaliplatin-, and DACHPt/m-treated groups at day 14. (c), Overall survival of mice treated with PBS, oxaliplatin or DACHPt/m. ** P $<0.001 \log$ rank test. (d), Ex vivo imaging of the tumor accumulation of Alexa 647-labeled DACHPt $/ \mathrm{m}$ in orthotopic tumors $24 \mathrm{~h}$ after injection. Strong fluorescence signal from DACHPt/m colocalized with the luminescence from C-26-luc tumor, indicating the preferential accumulation of the micelles in the orthotopic colon tumors.

\subsection{Efficacy of DACHPt/m against overt liver metastases of colon adenocarcinoma}

After confirming the in vivo efficacy of the micelles against primary tumors, we then evaluated their targeting ability in a vascularized metastatic model. Thus, we established overt hepatic metastases by injecting C-26-luc cells into the spleens of Balb/c mice (Supporting Figure S2a). The metastases were allowed to grow for 9 days and their bioluminescent signal was determined to be in the liver (Supporting Figure S2b). The formation of the overt hepatic metastasis was confirmed by histology (Supporting Figure S2c). Then, mice bearing these overt metastases were intravenously injected with PBS, free oxaliplatin at $8 \mathrm{mg} / \mathrm{kg}$, and DACHPt $/ \mathrm{m}$ at $3 \mathrm{mg} / \mathrm{kg}$ on days 0,3 , and 6 , and the activity of the drugs was followed by IVIS. Bioluminescence results demonstrated that 
DACHPt $/ \mathrm{m}$ effectively inhibited the growth of overt liver metastases (Figure $2 \mathrm{a} ; \mathrm{P}<0.05$ to both PBS and oxaliplatin). Because on day 16, mice treated with PBS and oxaliplatin started to die, we stopped the measurement of tumor expansion and kept recording the survival rate. The overall survival of mice treated with DACHPt/m (only 1 of 5 mice dead by day 26 after starting the treatment) was significantly higher than for mice treated with PBS (all mice dead at day 24) and oxaliplatin (all mice dead at day 26) (Figure 2c; $\mathrm{P}<0.05 \log$ rank test). These data support the enhanced activity of DACHPt/m against overt liver metastasis from C-26-luc cells.

The accumulation of Alexa 647-labeled DACHPt/m in the metastatic sites $24 \mathrm{~h}$ after systemic administration was studied ex vivo. Accordingly, the fluorescent signal of DACHPt $/ \mathrm{m}$ corresponded with the bioluminescent signals of the metastases, while the signal from the micelles in the healthy areas of liver was comparable to background fluorescence (Figure 2d), indicating the selective accumulation of the micelles in the metastatic foci. This improved therapeutic efficacy and targeting ability of DACHPt $/ \mathrm{m}$ against these vascularized tumor models, i.e. orthotopic and overt metastasis, may be related to the EPR effect as the tumors at these stages present extensive angiogenesis, which allows the accumulation of nanocarriers $[9,30]$.

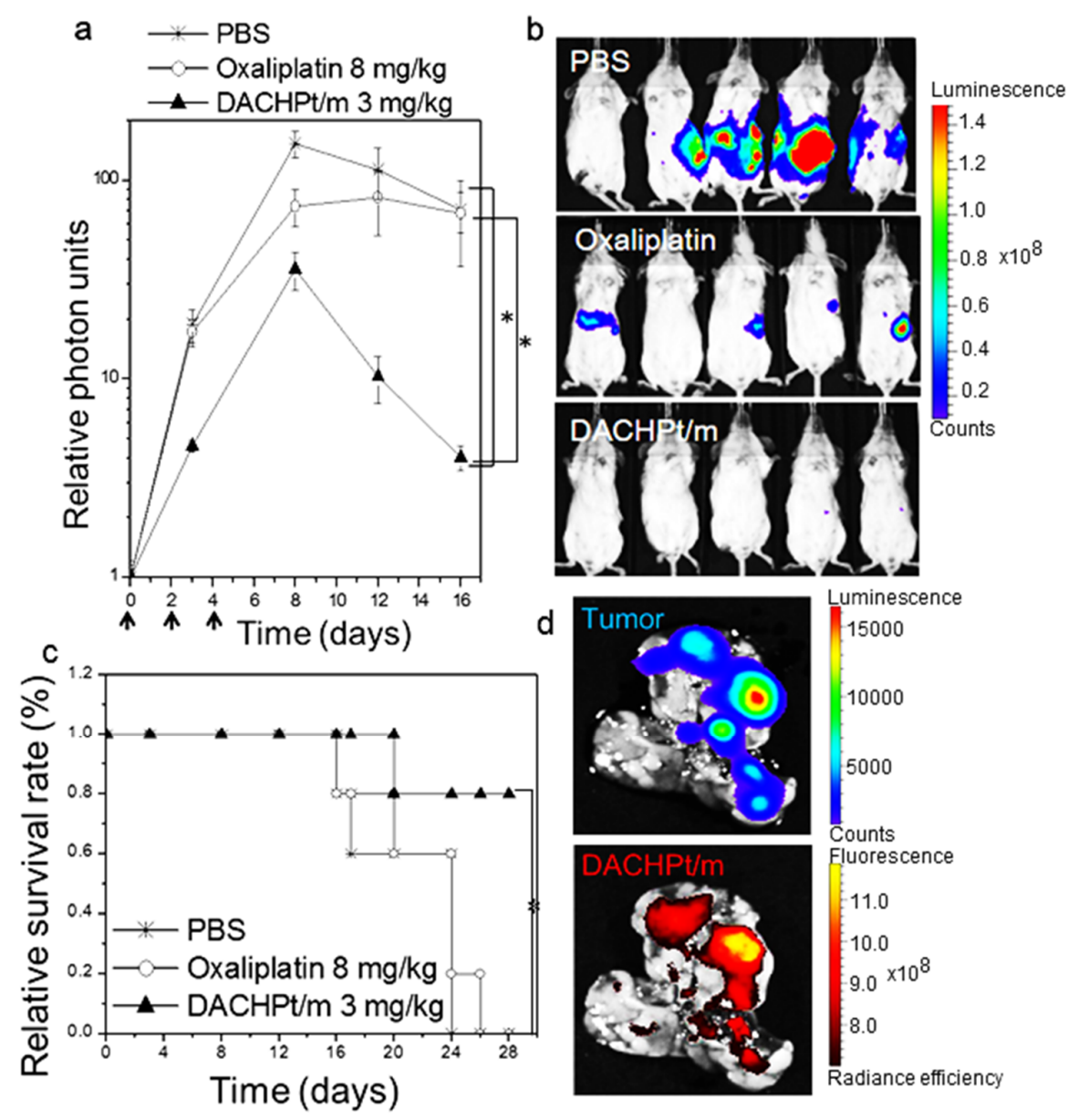

Figure 2. DACHPt-loaded micelles (DACHPt/m) inhibit the growth of C-26-luc overt liver metastases. (a), Longitudinal quantification analysis of bioluminescence signal of mice bearing C-26-luc overt liver metastases treated with oxaliplatin or DACHPt $/ \mathrm{m}$ on days 0,3 and 6 . Crosses, PBS; open circles, oxaliplatin at $8 \mathrm{mg} / \mathrm{kg}$; filled triangles, DACHPt/m at $3 \mathrm{mg} / \mathrm{kg}$. Data are expressed as mean $\pm \operatorname{SE}(n=5)$. Arrows indicate days of injection. $* P<0.05$. (b), Bioluminescent 
image of representative mice from PBS-, oxaliplatin-, and DACHPt $/ \mathrm{m}$-treated groups at day 13. (c), Overall survival of mice treated with PBS, oxaliplatin or DACHPt/m. * P $<0.05 \log$ rank test. (d), Ex vivo imaging of the accumulation of Alexa 647-labeled DACHPt $/ \mathrm{m}$ in metastatic tumors $24 \mathrm{~h}$ after injection. Colocalization of fluorescence from DACHPt $/ \mathrm{m}$ and luminescence from C-26-luc metastases indicate the preferential accumulation of the micelles in the overt liver metastases.

\subsection{Antitumor activity of DACHPt/m against preangiogenic liver metastases of colon adenocarcinoma}

Nanocarrier-mediated targeting of preangiogenic micrometastases is considered a challenging task due to the absence of neovasculature [8]. To study whether DACHPt/m can target preangiogenic metastasis, we established a model of preangiogenic hepatic metastasis by intrasplenically injecting C-26-luc cells. To determine the progress of the disease, liver tissues were harvested every 2 days after inoculation of the cancer cells and the histology of the metastases was studied by H\&E staining. Thus, while 2 days after inoculation no metastatic foci were detectable, micrometastases of approximately $100 \mu \mathrm{m}$ were observed at day 4 (Figure 3 and Table 1) and, 6 days after inoculation, the metastases reached approximately $300 \mu \mathrm{m}$ (Figure 3 and Table 1). Moreover, during the development of the metastasis, we assessed the liver damage of this tumor model by evaluating the markers of hepatocytes impairment, glutamic-pyruvic transaminase (GPT) and glutamic oxaloacetic transaminase (GOT) at different time points. Accordingly, the serum GPT

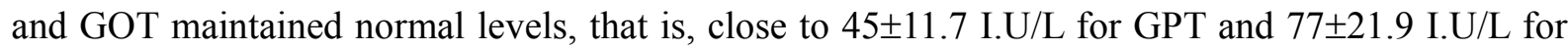
GOT, before day 4, and slightly elevated after day 6, indicating minimal liver damage (Supporting Figure S3). In addition, inflammatory cells were found at the metastatic sites from day 4 after inoculation (Table 1). As it has been reported that angiogenesis of liver micrometastases begins when the average diameter of the metastasis is $0.3-0.5 \mathrm{~mm}$, and they grow beyond the limits of the liver lobule [31, 32], in the prepared metastatic model, the metastases before day 6 (Table 1) were considered as preangiogenic.

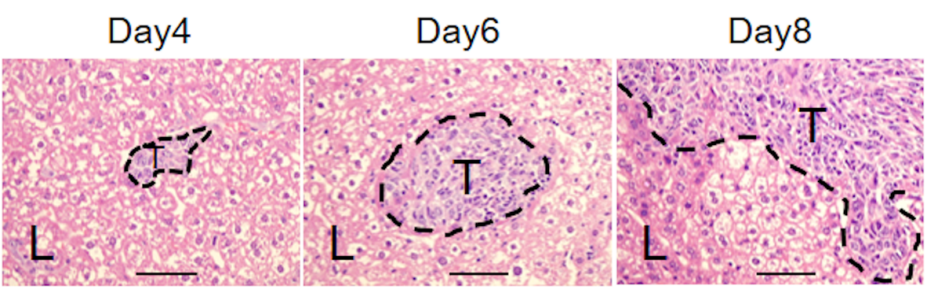

Figure 3. Establishment of preangiogenic liver metastatic model. H\&E stained liver sections showed micrometastases at days 4 and 6. Overt metastases were observed from day 8. T: metastatic tumor; L: normal liver. Scale bar: $100 \mu \mathrm{m}$.

Table 1. Appearance of liver metastasis and inflammatory cells at different time points after inoculation. Tumors smaller than $300 \mu \mathrm{m}$ were considered as preangiogenic micrometastases.

\begin{tabular}{ccc}
\hline Day & Inflammatory/metastatic cells $^{\mathrm{a}}$ & Tumor size (diameter) $^{\mathrm{a}}$ \\
\hline 2 & $-/-$ & - \\
4 & $+/+$ & $\sim 100 \mu \mathrm{m}$ \\
6 & $+/+$ & $\sim 300 \mu \mathrm{m}$ \\
8 & $+/+$ & $>300 \mu \mathrm{m}$ \\
10 & $+/+$ & $>300 \mu \mathrm{m}$ \\
\hline
\end{tabular}

${ }^{\text {a }}$ Results obtained by H\&E stained liver tissue sections from 3 mice. 
The antitumor activity of DACHPt/m against preangiogenic metastases was evaluated 4 days after inoculation of C-26-luc cells. The mice were treated with DACHPt/m at $3 \mathrm{mg} / \mathrm{kg}$, free oxaliplatin at $4 \mathrm{mg} / \mathrm{kg}$ and $8 \mathrm{mg} / \mathrm{kg}$ or PBS at days 0,3 and 6 , and the bioluminescent signal from the metastases was followed by IVIS. The micelles efficiently inhibited the growth of the metastases (Figure $4 \mathrm{a} ; \mathrm{P}<0.05$ ), whereas oxaliplatin at $8 \mathrm{mg} / \mathrm{kg}$ was toxic, leading to mice death, and oxaliplatin at $4 \mathrm{mg} / \mathrm{kg}$ was unable to reduce the metastasis progression (Figure $4 \mathrm{a}$ ). Moreover, 2 mice treated with PBS and 1 mice treated with oxaliplatin at $4 \mathrm{mg} / \mathrm{kg}$ died at day 14 , while all mice in DACHPt/m group were alive, displaying reduced bioluminescent signals (Figure $4 \mathrm{a}$ and $4 \mathrm{~b}$ ). Ex vivo microscopies of livers on day 15 showed multiple large tumor deposits for PBS-treated mice (Figure 4c). Conversely, the livers from DACHPt/m-treated mice did not present any visible metastasis (Figure 4c). In addition, the effect of the size of the micelles on their therapeutic activity against the preangiogenic metastases was evaluated, as we have recently reported that the size of sub-100 nm nanocarriers can affect their therapeutic activity in tumors with poor permeability [25]. Thus, along with usual DACHPt $/ \mathrm{m}$ having 30-nm diameter, we prepared larger DACHPt $/ \mathrm{m}$ with 70-nm diameter (Supporting Figure S4a and S4b), and studied the antitumor efficacy of both micelles. Accordingly, both $30-$ and $70-\mathrm{nm}$ micelles injected at $3 \mathrm{mg} / \mathrm{kg}$ on day 0,3 and 6 significantly inhibited the tumor growth in a comparable manner (Supporting Figure S4c), suggesting that the ability of DACHPt $/ \mathrm{m}$ to treat preangiogenic metastasis was not affected by their size in this model.

The accumulation of Alexa 647-labeled DACHPt/m in preangiogenic liver metastases of approximately $100 \mu \mathrm{m}$, which were obtained 4 days after inoculation of C-26-luc cells, was evaluated by IVIS $24 \mathrm{~h}$ after injection of the micelles. Ex vivo images showed the colocalization of the luminescent signal from C-26-luc metastases and the fluorescence signal from DACHPt/m (Figure 4d). At this point, the metastases are approximately $100 \mu \mathrm{m}$ in diameter and cannot be observed by naked eye, but their bioluminescent signal is detectable by IVIS. It is worth noting that the bioluminescent signal from these preangiogenic metastases (Figure 4d) is 10 times lower than that of overt metastases (Figure 2d), indicating the small size of these preangiogenic metastases. The areas with the highest luminescence from the metastatic cells and the fluorescence from the micelles appear to be colocalized (Figure 4d), suggesting the accumulation of micelles in the preangiogenic metastases. However, because the light from these small metastases and the fluorescence from Alexa 647-labeled DACHPt/m are being scattered in the liver tissue, the signal appears to be coming from large metastases rather than micrometastasis. Therefore, because of the insufficient resolution of IVIS for studying the distribution of the micelles in such small tumors, we proceeded to evaluate the accumulation of the micelles by using in vivo confocal laser-scanning microscopy (CLSM). 


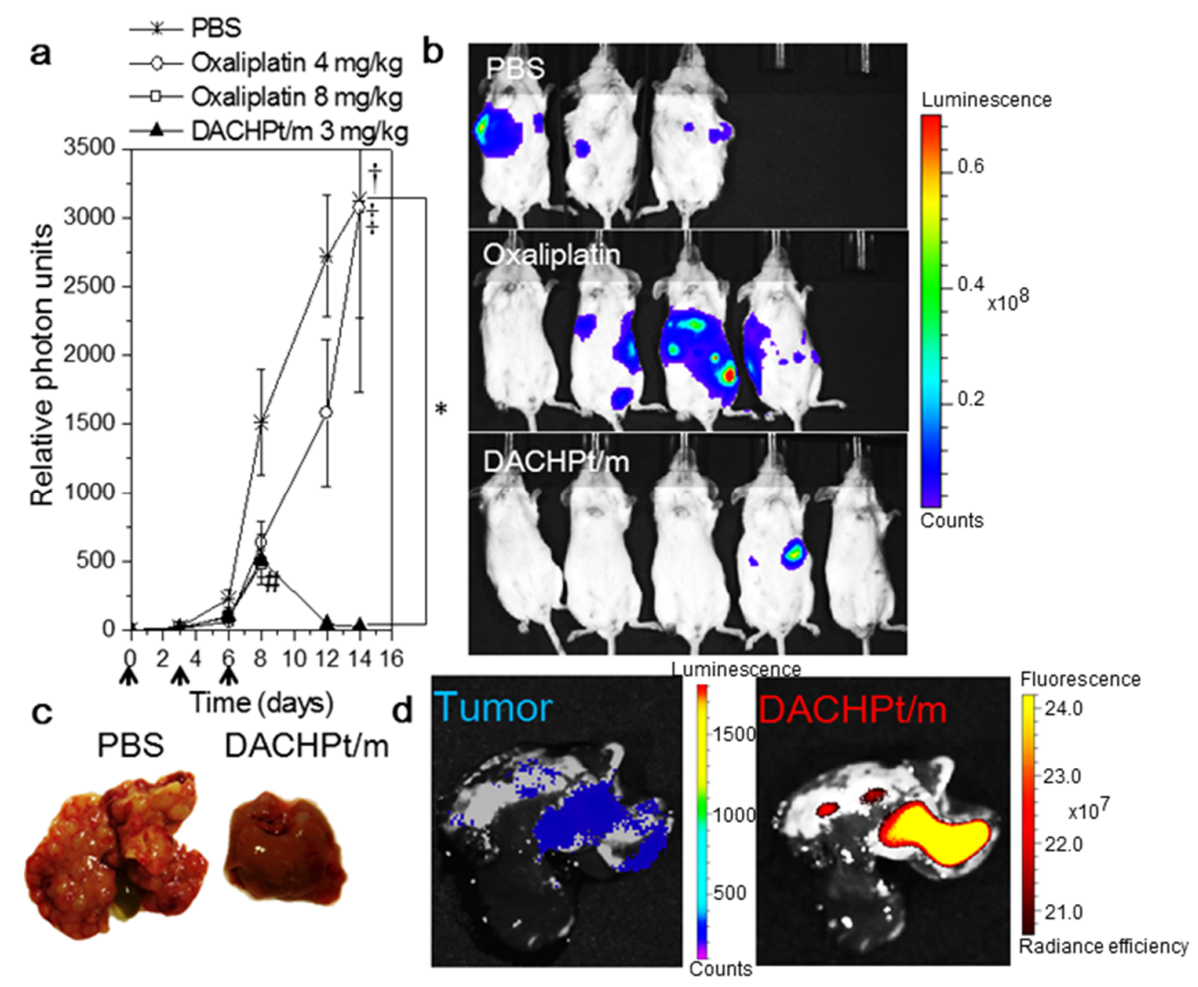

Figure 4. DACHPt-loaded micelles (DACHPt/m) inhibit the growth of C-26-luc preangiogenic liver metastases. (a), Longitudinal quantification analysis of bioluminescence signal of the mice treated with oxaliplatin or DACHPt/m on days 0, 3 and 6. Crosses, PBS; open circles, oxaliplatin at $4 \mathrm{mg} / \mathrm{kg}$; open squares, oxaliplatin at $8 \mathrm{mg} / \mathrm{kg}$; filled triangles, DACHPt $/ \mathrm{m}$ at $3 \mathrm{mg} / \mathrm{kg}$. Data are expressed as mean $\pm \mathrm{SE}(\mathrm{n}=5)$. Arrows indicate days of injection. $* \mathrm{P}<0.05$. \#: 3 of 5 mice dead. $\dagger$ : 2 of 5 mice dead. $\$$ : 1 of 5 mice dead. (b), Bioluminescent images of representative mice from PBS-, oxaliplatin $4 \mathrm{mg} / \mathrm{kg}$-, and DACHPt/m-treated groups at day 14. (c), Livers harvested from mice treated with PBS or DACHPt/m. (d), Ex vivo imaging of the accumulation of Alexa 647-labeled $\mathrm{DACHPt} / \mathrm{m}$ in metastatic tumors $24 \mathrm{~h}$ after injection.

\subsection{Real-time accumulation of DACHPt/m in preangiogenic liver metastases}

Encouraged by the significant efficacy of the micelles against the preangiogenic liver metastases, we studied the real-time accumulation of Alexa 647-labeled DACHPt/m in preangiogenic hepatic micrometastasis, which were prepared after intrasplenic inoculation of fluorescent C-26 cells expressing green fluorescence protein (C-26-GFP), by using in vivo CLSM attached to a high-speed resonance scanner. This microscope system allows real-time quantitative analyses of extravasation and tissue penetration of nanocarriers in living animals [29] (Supporting Figure S5). Thus, 4 days after inoculation, we intravitally detected liver metastasis of C-26-GFP cells with the size of approximately $200-\mu \mathrm{m}$ diameter (Figure 5a; green). It should be noticed that this metastasis is on the edge of the liver and, while on the right side of the metastasis there is liver tissue, on its left side there is no tissue. Then, Alexa 647-labeled DACHPt/m were intravenously injected, and their fluorescence was initially detected in the blood vessels of liver, but not within the metastasis (Figure 5a; red), indicating its preangiogenic status. Moreover, we observed that these preangiogenic metastasis presented strong autofluorescence when excited with Helium-Neon laser at $540 \mathrm{~nm}$ (Figure 5a, before injection and Supporting Figure S6), which may be correlated with the 
presence of Kupffer cells [33] and macrophages, as it has been reported that they become autofluorescent after maturation [34]. DACHPt/m gradually accumulated in the regions surrounding the C-26-GFP cluster within the metastatic niche (Supporting Movie S1), and $10 \mathrm{~h}$ after injection, the fluorescence from the micelles was clearly observed at the border of the cluster of cancer cells (Supporting Movie S1). Eighteen-hours after injection, evident accumulation was observed within the whole metastatic niche, i.e the cluster of C-26-GFP cell and the adjacent associated stroma, but not in normal liver (Figure 5a and Supporting Movie S1). By Z-stack volume reconstruction of metastatic niches at $18 \mathrm{~h}$, we verified this accumulation of micelles in the metastatic niche (Figure $5 \mathrm{~b}$ ), with colocalized micelles within the cluster of C-26-GFP cells observed in yellow, indicating the micelles penetration. By quantifying the fluorescence intensity of DACHPt $/ \mathrm{m}$, we found that the accumulation of DACHPt $/ \mathrm{m}$ gradually increased in the metastatic niche, while it decreased with time in normal liver tissue (Figure 5c). In addition, the accumulation of fluorescent-labeled $\mathrm{DACHPt} / \mathrm{m}$ at $18 \mathrm{~h}$ in metastatic niches from 3 different mice, which was expressed as a percentage of the maximum fluorescence intensity attained in the vascular region, was significantly higher than the accumulation in normal liver tissue (Figure $5 \mathrm{~d} ; \mathrm{P}<0.05$ ). These results suggest the enhanced accumulation of DACHPt $/ \mathrm{m}$ micelles to preangiogenic micrometastases.

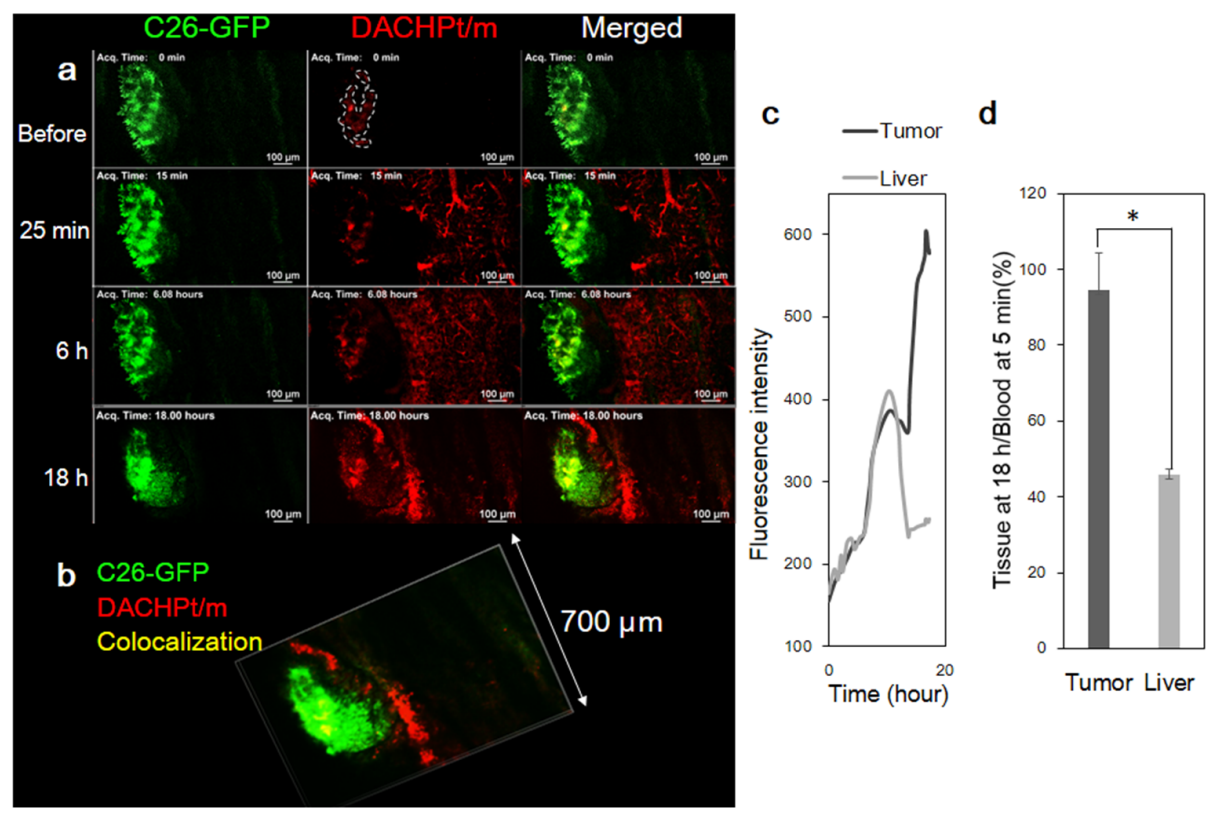

Figure 5. In vivo real-time microscopic observation of the accumulation of DACHPt-loaded micelles (DACHPt/m) in a preangiogenic metastasis. (a), Time-lapse snapshots of the accumulation of Alexa 647-labeled DACHPt/m (red) in a C-26-GFP (green) liver micrometastasis. Autofluorescence (red; dotted line) from Kupffer cells/macrophages was detectable within the metastasis before the injection of the micelles. Twenty-five minutes after injection, micelles were found circulating in the blood vessels of liver, but not in tumor. Six-hours after injection, the micelles were still detected within the vessels of liver, and gradually increasing the intensity at the surroundings of the metastasis. Eighteen-hours later, micelles specifically accumulated in the metastatic niche, i.e. tumor cells and surrounding microenvironment. (b), Z-stack volume reconstruction of metastatic niche showing the cluster of C-26-GFP (green) with Alexa 647-labeled DACHPt $/ \mathrm{m}$ (red) at $18 \mathrm{~h}$. (c), Time-lapse fluorescence intensity from Alexa 647-labeled DACHPt $/ \mathrm{m}$ in the metastatic niche and in healthy liver. (d), Accumulation of Alexa 647-labeled $\mathrm{DACHPt} / \mathrm{m}$ in the metastatic niche or healthy liver at $18 \mathrm{~h}$ expressed as a percentage of the 
maximum fluorescence intensity attained in the vascular region. Data are expressed as mean \pm SD $(\mathrm{n}=3)$.

\subsection{Effect of inflammatory microenvironment in preangiogenic metastasis on the accumulation of DACHPt-loaded micelles}

Several experimental and clinical studies support the role of inflammation on the ability of certain malignancies to metastasize to the liver $[3,5,6,13]$. This inflammatory microenvironment of early liver metastases, which involves a crosstalk between cancer cells, immune cells and stromal cells, engages in angiogenic signals necessary for metastases outgrowth [35]. It has been reported for a liver metastases model of C-26 cells [36], comparable to the one used in the present study, that the recruitment of inflammation-mediating Kupffer cells/macrophages, which release inflammatory cytokines, and activated hepatic stellate cells (HSCs), which secrete matrix metalloproteinase and vascular endothelial growth factor, into the early avacular metastasis was essential for tumor induced angiogenesis, and the later development of macrometastasis [36]. Therefore, we checked the presence of Kupffer cells/macrophages and activated HSCs by immunohistochemistry of the micrometastases of C-26-luc cells to determine the inflammatory status of the niches. Accordingly, we marked Kupffer cells/macrophages by using anti-CD68 (Cluster of Differentiation 68) and activated HSCs with anti- $\alpha$-smooth muscle actin (SMA) antibodies labeled with Alexa 647-secondary antibody, while C-26-luc cells were marked with anti-cytokeratin 20 (CK20) antibody labeled with Alexa 488-secondary antibody. The results showed that both Kupffer cells/macrophages (Figure 6a, red) and activated HSCs (Figure 6b, red) were present within the preangiogenic micrometastases (Figure $6 \mathrm{a}$ and $6 \mathrm{~b}$, red). These results reinforce our intravital microscopic observations showing strong autofluorescence (Figure 5a, before injection and Supporting Figure S6), which is associated with the presence of Kupffer cells and macrophages, within the metastases.

Macrophages and activated HSCs may also increase cyclooxygenase-2 (COX-2) levels in the tumor microenvironment $[35,37]$. COX-2 converts arachidonic acid to prostaglandins, which induces inflammatory reactions in damaged tissues, stimulating tumor cell proliferation, survival, motility and angiogenesis [38]. Therefore, we studied the COX-2 expression in preangiogenic metastases, probably induced by the macrophages and activated HSCs within the metastatic microenvironment, by using in vivo CLSM through intraperitoneally injecting COX-2 probe to mice bearing C-26-GFP liver metastasis. Four-hours after injecting the COX-2 probe, the microenvironment of the metastatic niche was specifically marked (Figure 7a; blue and Supporting Movie S2), indicating the inflammatory state of the micrometastasis. 
a

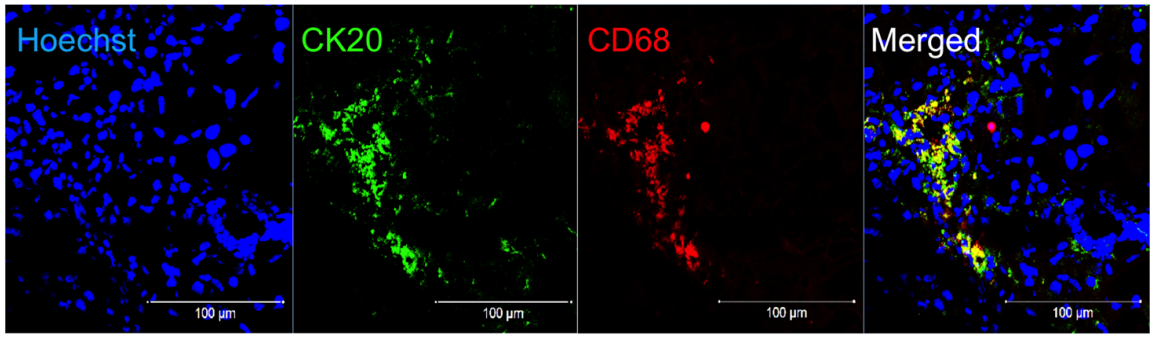

b

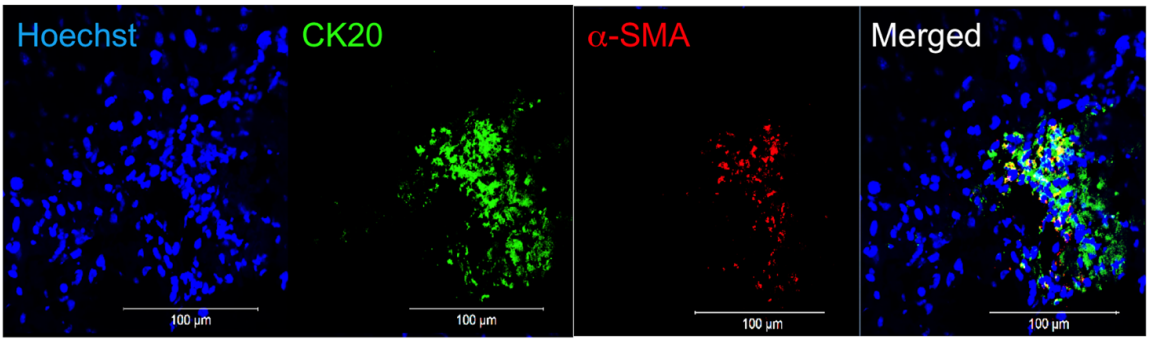

Figure 6. Immunofluorescence of liver micrometastasis. (a), Presence of Kupffer cells/ macrophages stained by anti-CD68 (red) within metastatic niches having C-26-luc cells marked with anti-CK20 (green). (b), Presence of hepatic stellate cells stained by anti-SMA (red) within metastatic niches having C-26-luc cells marked with anti-CK20 (green). Nuclei of cells were stained with Hoechst (blue).

The ability of DACHPt $/ \mathrm{m}$ to accumulate in the inflammatory micrometastasis was studied by in vivo CLSM via injection of both COX-2 probe and Alexa 555-labeled DACHPt $/ \mathrm{m}$. Twenty four-hours after injection, the colocalization fluorescent DACHPt/m (red) at C-26-GFP metastasis (green) having COX-2 positive microenvironment (blue) was observed as the white colored region (Figure 7b, merged, white). The Z-stack volume reconstruction of this metastatic niche further confirmed the accumulation of the micelles, as indicated by the white colored region corresponding to the colocalization of micelles, COX-2 probe and cancer cells, but not in healthy liver tissue (Figure 7c and Supporting Movie S3). Moreover, in the same mouse, we noticed that the fluorescent $\mathrm{DACHPt} / \mathrm{m}$ did not accumulate in COX-2-negative metastatic niches (Figure $7 \mathrm{~b}$ ). Interestingly, these COX-2-negative niches (Figure 7b) did not showed the autofluorescence associated with the presence of macrophages (Figure 5a, before injection and Supporting Figure S6). Thus, the fluorescence intensity from DACHPt/m in the COX-2 positive C-26-GFP metastasis was 3.4 times higher than that in the COX-2 negative metastasis (Figure 7d), indicating that DACHPt/m accumulate in preangiogenic metastases of C-26 with increased levels of COX-2. These results suggest that the inflammatory microenvironment of preangiogenic metastases may be necessary for the accumulation of the micelles. 

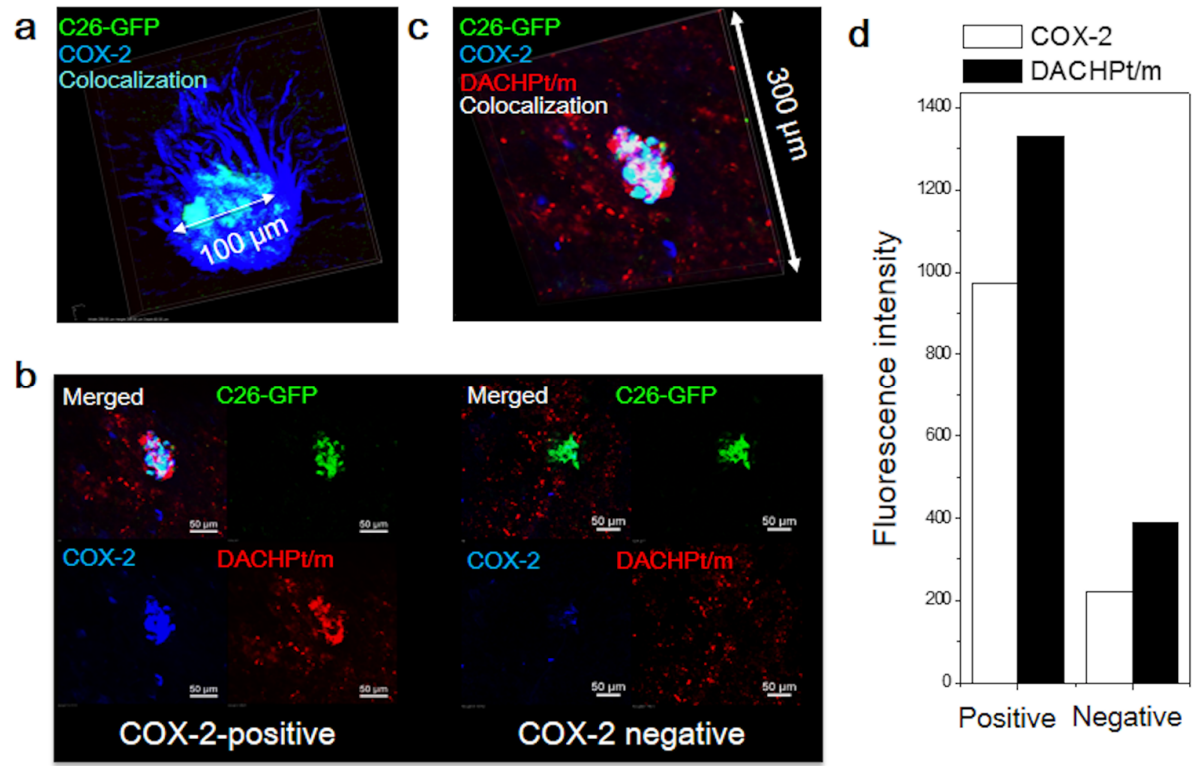

Figure 7. In vivo microscopic observation of the accumulation DACHPt-loaded micelles (DACHPt/m) in COX-2 positive metastatic niches. (a), COX-2 (blue) expression in $100 \mu \mathrm{m}$ C-26-GFP (green) micrometastasis marked with COX-2 probe. (b), In vivo microscopy of accumulation of Alexa 555-labeled DACHPt/m (red) in COX-2-positive and COX-2-negative micrometastases of C-26-GFP (green) from the same mouse $24 \mathrm{~h}$ after injection of the micelles. The colocalization of DACHPt/m, C-26-GFP and COX-2 probe is observed in white. Micelles only accumulated in COX-2-positive metastasis. (c), Z-stack volume reconstruction of COX-2-positive (blue) metastasis of C-26-GFP (green) having Alexa 555-labeled DACHPt/m (red). White color corresponds to colocalization of C-26-GFP, COX-2 probe and DACHPt $/ \mathrm{m}$. (d), Fluorescence intensity of DACHPt/m and COX-2-probe in COX-2-positive and COX-2-negative metastasis of C-26-GFP

3.6 Effect of celecoxib-pretreatment on the accumulation of DACHPt-loaded micelles in preangiogenic metastases

Based on the aforementioned results, we studied the influence of COX-2 on the accumulation of the micelles in preangiogenic metastasis by pretreating a mouse bearing C-26-GFP liver metastases with celecoxib, which is a clinically used anti-inflammatory drug and a selective COX-2 inhibitor [39]. Thus, celecoxib was intraperitoneally injected at $5 \mathrm{mg} / \mathrm{kg} 24 \mathrm{~h}$ before injecting the COX-2 probe and fluorescent DACHPt $/ \mathrm{m}$. Although the tumors were imaged in real-time for $16 \mathrm{~h}$ after injecting COX-2 probe and Alexa 555-labeled DACHPt/m, neither specific accumulation of COX-2 probe nor DACHPt/m were found in the metastases, even in $300 \mu \mathrm{m}$ metastasis (Figure $8 \mathrm{a}$ ). The Z-stack volume reconstruction of the metastatic niches confirmed these results within the whole volume of the metastatic niches (Figure 8b). 

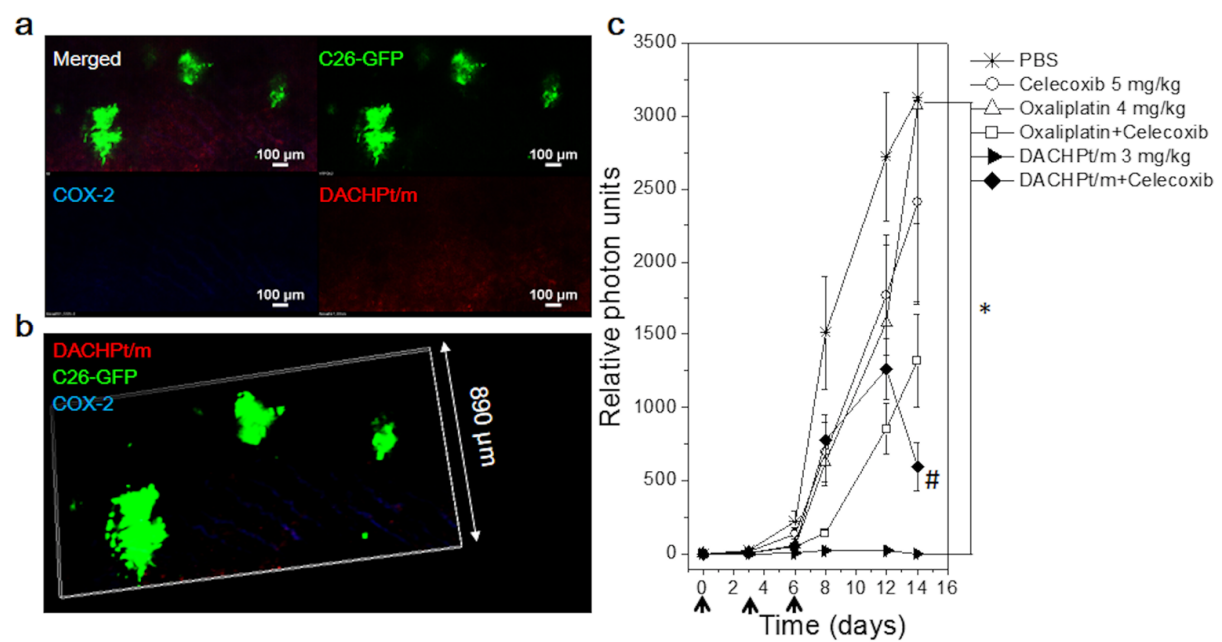

Figure 8. Effect of celecoxib on the targeting ability of DACHPt-loaded micelles (DACHPt/m) in preangiogenic liver metastases. (a), C-26-GFP (green) metastases from a mouse pretreated with celecoxib at $5 \mathrm{mg} / \mathrm{kg} 24 \mathrm{~h}$ before imaging. Neither COX-2 probe (blue) nor Alexa 555-labeled $\mathrm{DACHPt} / \mathrm{m}$ (red) were detected in these metastases. (b), Z-stack volume reconstruction of C-26-GFP (green) metastases from celecoxib-pretreated mouse. (c), Antitumor effect of DACHPt $/ \mathrm{m}$ and free oxaliplatin against preangiogenic metastases after pretreatment with celecoxib. C-26-luc liver metastases were imaged every 2 days and longitudinally quantified for bioluminescence signal. Mice were treated with oxaliplatin or DACHPt $/ \mathrm{m}$ on days 0,3 and 6 . Celecoxib was injected at 5 $\mathrm{mg} / \mathrm{kg} 24 \mathrm{~h}$ before starting the anticancer treatment. Crosses, PBS; open circles, celecoxib at 5 $\mathrm{mg} / \mathrm{kg}$; open triangles, oxaliplatin at $4 \mathrm{mg} / \mathrm{kg}$; open squares, oxaliplatin and celecoxib; filled triangles, DACHPt $/ \mathrm{m}$ at $3 \mathrm{mg} / \mathrm{kg}$; filled diamonds, DACHPt $/ \mathrm{m}$ and celecoxib. Data are expressed as mean $\pm \operatorname{SE}(\mathrm{n}=5)$. Arrows indicate days of injection. $* \mathrm{P}<0.05$. $\#: 2$ of 5 mice dead.

The effect of inhibiting COX-2 on the antitumor effect of DACHPt/m against preangiogenic metastasis was studied by pretreating mice bearing C-26-luc liver metastasis with celecoxib at 5 $\mathrm{mg} / \mathrm{kg} 24 \mathrm{~h}$ before starting the administration of micelles or oxaliplatin. Then, DACHPt $/ \mathrm{m}$ at 3 $\mathrm{mg} / \mathrm{kg}$ or oxaliplatin at $4 \mathrm{mg} / \mathrm{kg}$ were intravenously injected on days 0,3 and 6 . Mice treated only with celecoxib were also used as control. Thus, while the anticancer effect of free oxaliplatin was strengthened after celecoxib pretreatment (Figure 8c), DACHPt/m were less effective than without celecoxib pretreatment (Figure 8c), and 2 out of 5 mice in the DACHPt/m plus celecoxib group died at day 14 (Figure 8c, \#) due to the prominent outgrowth of their metastases. These results suggest that the targeting of $\mathrm{DACHPt} / \mathrm{m}$ to preangiogenic metastatic niches may be affected by COX-2-associated inflammatory conditions.

\section{Discussion}

Our results demonstrated that DACHPt/m were effective against both vascularized overt metastasis and preangiogenic metastasis in liver. While the improved anticancer activity against vascularized metastasis can be associate with the EPR effect, we found that the ability of the micelles to target preangiogenic metastases was associated with the COX-2-related inflammatory conditions of the niches. To our knowledge, this is the first report demonstrating the targeting capability of systemically injected nanocarriers to preangiogenic metastasis. This ability may provide a novel approach for early diagnosis and treatment of metastases. 
Intravenously injected DACHPt $/ \mathrm{m}$ showed prolonged circulation in the bloodstream and gradually penetrated into the metastatic niche from its surroundings. Because the cancer cells as well as stromal cells and immune cells residing in the microenvironment of the preangiogenic metastases can release cytokines (14) that augment the permeability of the neighboring tissues, the penetration of the micelles may be facilitated by enhanced intraendothelial/interendothelial passage from blood vessels adjacent to the metastatic niches. Accordingly, inflammatory stimuli associated with COX-2, prostaglandins and vascular endothelial growth factor can increase transcellular and paracellular permeability, by transporting macromolecules via caveolae-mediated transcytosis and by widening the intercellular space after dissociation of cell-cell junctions between endothelial cells and contraction of their cytoskeleton, respectively [40]. Moreover, our results showing that the efficacy of DACHPt $/ \mathrm{m}$ having $70-\mathrm{nm}$ diameter was comparable to that of DACHPt $/ \mathrm{m}$ with $30-\mathrm{nm}$ diameter against the preangiogenic metastases support the possibility of interendothelial migration of micelles into the inflammatory micrometastatic foci. Besides the enhanced permeability of the inflammatory micrometastases to polymeric micelles, there seems to be a retention mechanism for the micelles within the metastatic niche, as observed from the intravital microscopies, which may be associated with the uptake of the micelles by scavenging cells like macrophages and Kupffer cells inside the metastatic site. Thus, the cytotoxic effect of DACHPt $/ \mathrm{m}$ against preangiogenic liver metastases may be exerted not only on the cancer cells, but also on the metastasis-associated immune cells and stromal cells. Because the critical role of such metastasis-associated cells in the promotion of metastasis [35], targeting the whole metastatic niche may be an efficient therapeutic strategy for removing micrometastases.

The precluded accumulation of DACHPt/m in metastatic foci without COX-2 expression reinforces the assisting role of the inflammatory microenvironment of the metastatic niches on the micelles' targeting. The selective inhibition of COX-2 by pretreatment with celecoxib may downregulate the cytokines, which increase the permeability of the microvasculature, reducing the penetration of the micelles into the metastatic site. As celecoxib can also induce apoptosis of macrophages [41], the retention of the micelles at the micrometastases may be hindered by reduced macrophage uptake. For selectively targeting non-inflammatory metastases, the installation of ligand molecules, which can target epitopes specifically expressed on metastatic cells, on the surface of polymeric micelles [28, 42-44] may provide improved cell uptake and enhanced tumor accumulation. Moreover, by using ligand-installed micelles, it may be possible to achieve specific drug delivery to cellular sub-populations within the metastatic foci. Therefore, the efficacy of ligand-installed polymeric micelles against micrometastatic disease is currently under investigation in our group.

Inflammation of micrometastases is strongly related with their ability to trigger the formation of new blood vessels [3-6, 35]. Moreover, the inflammation of preangiogenic micrometastases has been associated with the angiogenic switch of dormant tumors $[45,46]$. The acquisition of this angiogenic switch can initiate the outgrowth of dormant metastases [47]. In this way, polymeric micelles may also offer the possibility to target dormant metastatic disease that have become activated by inflammatory triggers, thus, retricting the onset of the metastatic disease. Although our study is limited to the inflammatory conditions in liver micrometastases of colon cancer, comparable inflammatory responses have been found in micrometastases from various cancers in other organs [5]. Therefore, the study of the micelles accumulation in other preangiogenic metastatic models will provide further insights regarding the targeting mechanisms. 


\section{Conclusion}

Our findings indicate that DACHPt/m can provide a wide therapeutic strategy against cancer, not only for targeting primary tumors and overt liver metastases showing EPR effect, but also early preangiogenic metastases based on the inflammatory microenvironment of the metastatic niche. This ability to target preangiogenic metastases suggests the advantage of polymeric micelles for restricting the development and growth of metastasis before they cause irreversible harm to the patient. As a wide range of reporter and bioactive agents can be incorporated in the core of polymeric micelles, a broad spectrum of polymeric micelles for diagnostic and therapeutic applications with clinical potential against metastatic disease can be envisioned.

\section{Acknowledgements}

This study was supported by the Funding Program for World-Leading Innovative R\&D on Science and Technology (FIRST Program) from Japan Society for the Promotion of Science (JSPS), Center of Innovation (COI), Program from Japan Science and Technology Agency (JST), and Takeda Science Foundation, as well as Grants-in-Aid for Young Scientists (B; No. 23700526 and No. 25750172 to H.C.; A; No. 24689051 to YM) and Challenging Exploratory Research (No. 24659584 to $\mathrm{YM})$.

\section{References}

[1] P. Mehlen, A. Puisieux, Metastasis: a question of life or death, Nat. Rev. Cancer 6 (2006) 449-458.

[2] J. Ferlay, I. Soerjomataram, M. Ervik, R. Dikshit, S. Eser, C. Mathers, M. Rebelo, DM. Parkin, D. Forman, Bray, F.

GLOBOCAN 2012 v1.0, Cancer Incidence and Mortality Worldwide: IARC CancerBase No. 11 [Internet]. (Would Hearth Organization)

[3] P.S. Steeg, Tumor metastasis: mechanistic insights and clinical challenges, Nat. Med. 12 (2006) 895-904.

[4] L. Wan, K. Pantel, Y. Kang, Tumor metastasis: moving new biological insights into the clinic, Nat. Med. 19 (2013) 1450-1464.

[5] A.F. Chambers, A.C. Groom, I.C. MacDonald, Metastasis: dissemination and growth of cancer cells in metastatic sites, Nat. Rev. Cancer 2 (2002) 563-572.

[6] S. Valastyan, R.A. Weinberg, Tumor metastasis: molecular insights and evolving paradigms, Cell 147 (2011) 275-292.

[7] P. Carmeliet, R.K. Jain, Principles and mechanisms of vessel normalization for cancer and other angiogenic diseases, Nat. Rev. Drug Discov. 10 (2011) 417-427.

[8] A. Schroeder, D.A. Heller, M.M. Winslow, J.E. Dahlman, G.W. Pratt, R. Langer, T. Jacks, D.G. Anderson, Treating metastatic cancer with nanotechnology, Nat. Rev. Cancer 12 (2011) 39-50.

[9] Y. Matsumura, H. Maeda, A new concept for macromolecular therapeutics in cancer chemotherapy: mechanism of tumoritropic accumulation of proteins and the antitumor agent smancs, Cancer Res. 46 (1986) 6387-6392.

[10] X. Yao, Y. Yoshioka, T. Morishige, Y. Eto, H. Watanabe, Y. Okada, H. Mizuguchi, Y. Mukai, N. Okada, S. Nakagawa, Systemic administration of a PEGylated adenovirus vector with a cancer-specific promoter is effective in a mouse model of metastasis, Gene Ther. 16 (2009) 1395-1404.

[11] M. Sumitomo, F. Koizumi, T. Asano, A. Horiguchi, K. Ito, T. Asano, T. Kakizoe, M. Hayakawa, Y. Matsumura, Novel SN-38-incorporated polymeric micelle, NK012, strongly suppresses renal cancer progression, Cancer Res. 68 (2008) 1631-1635.

[12] A.T. Perez, G.H. Domenech, C. Frankel, C.L. Vogel, Pegylated Liposomal Doxorubicin (Doxil@) for Metastatic Breast Cancer: The Cancer Research Network, Inc., Experience, Cancer Invest. 20 (2002) 22-29.

[13] J. Spicer, P. Brodt, L. Ferri, Role of CXC Chemokines and Receptors in Liver Metastasis - Impact on Liver 
Resection-Induced Engraftment and Tumor Growth, in: P. Brodt (Ed.), Liver Metastasis: Biology and Clinical Management, Springer, 2011, pp. 155-185.

[14] H.F. Dvorak, Vascular permeability factor/vascular endothelial growth factor: a critical cytokine in tumor angiogenesis and a potential target for diagnosis and therapy, J. Clin. Oncol. 20 (2002) 4368-4380.

[15] K. Kataoka, A. Harada, Y. Nagasaki, Block copolymer micelles for drug delivery: design, characterization and biological significance, Adv. Drug Deliv. Rev. (2012).

[16] N. Nishiyama, K. Kataoka, Current state, achievements, and future prospects of polymeric micelles as nanocarriers for drug and gene delivery, Pharmacol. Ther. 112 (2006) 630-648.

[17] Y. Matsumura, K. Kataoka, Preclinical and clinical studies of anticancer agent - incorporating polymer micelles, Cancer Sci. 100 (2009) 572-579.

[18] R. Plummer, R. Wilson, H. Calvert, A. Boddy, M. Griffin, J. Sludden, M. Tilby, M. Eatock, D. Pearson, C. Ottley, A Phase I clinical study of cisplatin-incorporated polymeric micelles (NC-6004) in patients with solid tumours, Br. J. Cancer 104 (2011) 593-598.

[19] K.R. Hess, G.R. Varadhachary, S.H. Taylor, W. Wei, M.N. Raber, R. Lenzi, J.L. Abbruzzese, Metastatic patterns in adenocarcinoma, Cancer 106 (2006) 1624-1633.

[20] S.R. Alberts, L.D. Wagman, Chemotherapy for colorectal cancer liver metastases, The Oncologist 13 (2008) 1063-1073.

[21] C. Penna, B. Nordlinger, Colorectal metastasis (liver and lung), Surg. Clin. North Am. 82 (2002) 1075-1090.

[22] H. Cabral, N. Nishiyama, S. Okazaki, H. Koyama, K. Kataoka, Preparation and biological properties of dichloro (1, 2-diaminocyclohexane) platinum (II)(DACHPt)-loaded polymeric micelles, J. Control. Release, 101 (2005) 223 -232.

[23] H. Cabral, N. Nishiyama, K. Kataoka, Optimization of (1,2-diamino-cyclohexane)platinum(II)-loaded polymeric micelles directed to improved tumor targeting and enhanced antitumor activity, J. Control. Release, 121 (2007) 146-155.

[24] M. Murakami, H. Cabral, Y. Matsumoto, S. Wu, M.R. Kano, T. Yamori, N. Nishiyama, K. Kataoka, Improving drug potency and efficacy by nanocarrier-mediated subcellular targeting, Sci. Transl. Med. 3 (2011) 64ra2.

[25] H. Cabral, Y. Matsumoto, K. Mizuno, Q. Chen, M. Murakami, M. Kimura, Y. Terada, M.R. Kano, K. Miyazono, M. Uesaka, N. Nishiyama, K. Kataoka, Accumulation of sub-100 nm polymeric micelles in poorly permeable tumours depends on size, Nat. Nanotech. 6 (2011) 815-823.

[26] M. Rafi, H. Cabral, M. Kano, P. Mi, C. Iwata, M. Yashiro, K. Hirakawa, K. Miyazono, N. Nishiyama, K. Kataoka, Polymeric micelles incorporating (1, 2-diaminocyclohexane) platinum (II) suppress the growth of orthotopic scirrhous gastric tumors and their lymph node metastasis, J. Control. Release 159 (2012) 189-196.

[27] H. Cabral, M. Murakami, H. Hojo, Y. Terada, M.R. Kano, U.-i. Chung, N. Nishiyama, K. Kataoka, Targeted therapy of spontaneous murine pancreatic tumors by polymeric micelles prolongs survival and prevents peritoneal metastasis, Proc. Natl. Acad. Sci. U S A. 110 (2013) 11397-11402.

[28] S. Deshayes, H. Cabral, T. Ishii, Y. Miura, S. Kobayashi, T. Yamashita, A. Matsumoto, Y. Miyahara, N. Nishiyama, K. Kataoka, Phenylboronic Acid-Installed Polymeric Micelles for Targeting Sialylated Epitopes in Solid Tumors, J. Am. Chem. Soc. 135 (2013) 15501-15507.

[29] Y. Matsumoto, T. Nomoto, H. Cabral, Y. Matsumoto, S. Watanabe, R.J. Christie, K. Miyata, M. Oba, T. Ogura, Y. Yamasaki, Direct and instantaneous observation of intravenously injected substances using intravital confocal micro-videography, Biomed. Opt. Express 1 (2010) 1209-1216.

[30] H. Maeda, J. Wu, T. Sawa, Y. Matsumura, K. Hori, Tumor vascular permeability and the EPR effect in macromolecular therapeutics: a review, J. Control. Release, 65 (2000) 271-284.

[31] M.S. Solaun, L. Mendoza, M. De Luca, V. Gutierrez, M.P. Lopez, E. Olaso, L. Sim, B. Kim, F. Vidal-Vanaclocha, Endostatin inhibits murine colon carcinoma sinusoidal - type metastases by preferential targeting of hepatic sinusoidal endothelium, Hepatology 35 (2002) 1104-1116.

[32] S. Paku, K. Lapis, Morphological aspects of angiogenesis in experimental liver metastases, Am. J. Pathol. 143 
(1993) 926.

[33] J. Dijkstra, W. Van Galen, C. Hulstaert, D. Kalicharan, F. Roerdink, G. Scherphof, Interaction of liposomes with Kupffer cells in vitro, Exp. Cell. Res. 150 (1984) 161-176.

[34] E. Walker, E. Akporiaye, N. Warner, C. Stewart, Characterization of subsets of bone marrow-derived macrophages by flow cytometry analysis, J. Leukoc. Biol. 37 (1985) 121-136.

[35] G.G. Van den Eynden, A.W. Majeed, M. Illemann, P.B. Vermeulen, N.C. Bird, G. Høyer-Hansen, R.L. Eefsen, A.R. Reynolds, P. Brodt, The multifaceted role of the microenvironment in liver metastasis: biology and clinical implications, Cancer Res. 73 (2013) 2031-2043.

[36] X. Yang, P. Lu, Y. Ishida, W.A. Kuziel, C. Fujii, N. Mukaida, Attenuated liver tumor formation in the absence of CCR2 with a concomitant reduction in the accumulation of hepatic stellate cells, macrophages and neovascularization, Int. J. Cancer 118 (2006) 335-345.

[37] Y.Q. Wang, J.M. Luk, K. Ikeda, K. Man, A.C. Chu, K. Kaneda, S. Tat Fan, Regulatory role of vHL/HIF-1 $\alpha$ in hypoxia-induced VEGF production in hepatic stellate cells, Biochem. Biophys. Res. Commun. 317 (2004) 358-362.

[38] G. Lorusso, C. Rüegg, The tumor microenvironment and its contribution to tumor evolution toward metastasis, Histochem. Cell Biol. 130 (2008) 1091-1103.

[39] C.J. Hawkey, COX-2 inhibitors, Lancet 353 (1999) 307-314.

[40] P. Kumar, Q. Shen, C.D. Pivetti, E.S. Lee, M.H. Wu, S.Y. Yuan, Molecular mechanisms of endothelial hyperpermeability: implications in inflammation, Expert Rev. Mol. Med. 11 (2009) e19.

[41] J. Subhashini, S. Mahipal, P. Reddanna, Anti-proliferative and apoptotic effects of celecoxib on human chronic myeloid leukemia in vitro, Cancer Lett. 224 (2005) 31-43.

[42] Y. Miura, T. Takenaka, K. Toh, S. Wu, H. Nishihara, M.R. Kano, Y. Ino, T. Nomoto, Y. Matsumoto, H. Koyama, Cyclic RGD-Linked Polymeric Micelles for Targeted Delivery of Platinum Anticancer Drugs to Glioblastoma through the Blood-Brain Tumor Barrier, ACS Nano 7 (2013) 8583-8592.

[43] N. Nasongkla, X. Shuai, H. Ai, B.D. Weinberg, J. Pink, D.A. Boothman, J. Gao, cRGD - functionalized polymer micelles for targeted doxorubicin delivery, Angew. Chem. Int. Ed. Engl. 116 (2004) 6483-6487.

[44] M. Oba, K. Aoyagi, K. Miyata, Y. Matsumoto, K. Itaka, N. Nishiyama, Y. Yamasaki, H. Koyama, K. Kataoka, Polyplex micelles with cyclic RGD peptide ligands and disulfide cross-links directing to the enhanced transfection via controlled intracellular trafficking, Mol. Pharm. 5 (2008) 1080-1092.

[45] J.A. Joyce, J.W. Pollard, Microenvironmental regulation of metastasis, Nat. Rev. Cancer 9 (2008) 239-252.

[46] P. Schwartsburd, Age-promoted creation of a pro-cancer microenvironment by inflammation: pathogenesis of dyscoordinated feedback control, Mech. Ageing Dev. 125 (2004) 581-590.

[47] L. Holmgren, M.S. O'Reilly, J. Folkman, Dormancy of micrometastases: balanced proliferation and apoptosis in the presence of angiogenesis suppression, Nat. Med. 1 (1995) 149-153.

[48] N. Nishiyama, S. Okazaki, H. Cabral, M. Miyamoto, Y. Kato, Y. Sugiyama, K. Nishio, Y. Matsumura, K. Kataoka, Novel cisplatin-incorporated polymeric micelles can eradicate solid tumors in mice, Cancer Res. 63 (2003) 8977-8983. 


\section{Graphical Abstract}

Polymeric micelles, which efficiently target vascularized tumors by EPR effect, can accumulate in preangiogenic micrometastases without neovascularization by exploiting the inflammatory microenvironment of the metastatic niches, thereby, enhancing their efficacy.
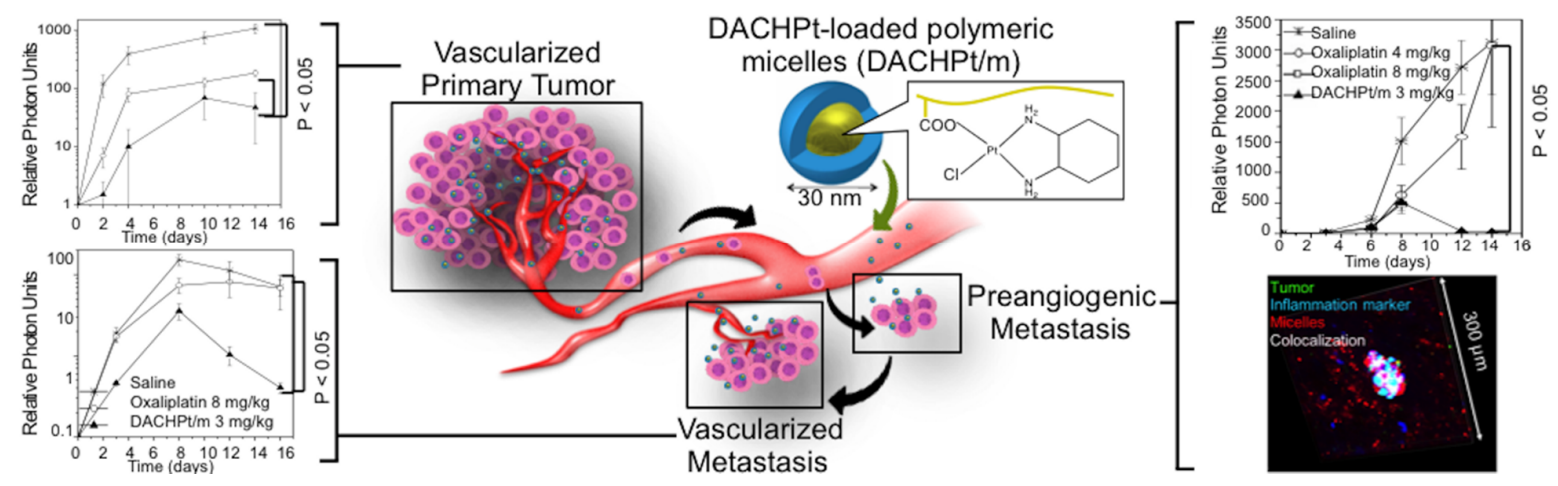